\title{
Computed tomography findings of acute abdomen: a pictorial essay
}

\author{
Elif Hocaoglu*1, Inci Kizildag Yirgin ${ }^{1}$, Sema Aksoy ${ }^{1}$, İrem Erdil ${ }^{1}$, Ercan Inci ${ }^{1}$, Gokhan Adas ${ }^{2}$ \\ ${ }^{1}$ Departments of Radiology, Bakirkoy Dr. Sadi Konuk Training and Research Hospital, Istanbul, Turkey \\ ${ }^{2}$ Departments of Surgery, Bakirkoy Dr. Sadi Konuk Training and Research Hospital, Istanbul, Turkey
}

Received: June 30, 2014

Accepted: November 4, 2014 Online Published: November 30, 2014

DOI: $10.5430 / j b g c . v 5 n 1 p 11$

URL: http://dx.doi.org/10.5430/jbgc.v5n1p11

\begin{abstract}
Acute abdomen can be defined as a clinical condition often requires emergency surgical therapy and characterized by severe abdominal pain with tenderness that develops over a short period of time, generally less than 24 hours. There are a variety of conditions that can present clinically with acute abdomen such as: inflammatory, vascular, mechanic, traumatic. In many cases, the clinical presentation is similar, independent of etiology. The radiological imaging plays very important role to determine the need for operative intervention and initiate appropriate therapy. Our aim is to describe the computed tomography findings of the most common conditions of acute abdomen excluding trauma and pediatric or obstetric patients.
\end{abstract}

Key Words: Acute abdomen, Radiologic diagnosis, Computed tomography

\section{Introduction}

The term "acute abdomen" can be defined as a clinical condition often requires emergency surgical therapy and characterized by severe abdominal pain with tenderness that develops over a short period of time, generally less than 24 hours. There are a variety of conditions that can present clinically with acute abdomen such as: inflammatory, vascular, mechanic, traumatic. ${ }^{[1]}$

Four or five percent of the patients who admitted to the emergency department have acute abdominal pain. In many cases, the clinical presentation is similar and independent of etiology. With careful physical examination, thorough history and laboratory findings of the patients, correct diagnosis can be achieved only in a minority of them. Radiological imaging have increased the accurate diagnosis rates and plays very important role to determine the need for operative intervention and initiate appropriate therapy. ${ }^{[1,2]}$
Conventional radiography, ultrasonography (US), and computed tomography (CT) are used in diagnosis of patients with acute abdomen. ${ }^{[1-3]}$ Ahn et al. ${ }^{[4]}$ concluded "abdominal radiographs are not sensitive in the evaluation of adult patients presenting to the emergency department with nontraumatic abdominal pain". In some cases, such as those of patients suspected of having bowel obstruction, perforated viscus, urinary tract calculi, or foreign bodies, conventional radiography has been reported to have good accuracy. ${ }^{[4-6]}$

While US is uses in evaluation of the biliary disease and gynecologic conditions as the initial imaging study, CT has emerged as the primary imaging modality for evaluation of the acute abdomen. ${ }^{[7]}$ US is the most frequently performed modality for right upper quadrant pain in the diagnosis of acute cholecystitis. ${ }^{[8]}$ In two studies, ${ }^{[9,10]}$ US findings led to an alteration in treatment management for $22 \%$ of patients.

The American College of Radiology suggests primarily an

*Correspondence: Elif Hocaoglu; Email: drelifhocaoglu@ hotmail.com; Address: TevfikSağlam Cad. No:11, Zuhuratbaba 34147, Bakırköy, Istanbul, Turkey. 
abdominal CT with contrast in patients with acute abdominal pain. ${ }^{[11]}$ Others prefer an ultrasound as the dominant imaging technique mainly because it is easily accessible and has no ionising radiation. ${ }^{[12,13]}$ A major disadvantage of US is that it is operator-dependent modality. Randen et al. ${ }^{[3]}$ found that the sensitivity of CT was significantly higher than that of ultrasound in detecting appendicitis and diverticulitis. For acute cholecystitis and bowel obstruction there were no significant differences in accuracy between US and CT. The etiology of the obstruction is better evaluated with CT than with US. ${ }^{[3]}$ An another study did not show any significant difference in accuracy between US and CT in detecting diverticulitis, but CT is more likely to detect complications of acute diverticulitis. ${ }^{[14]}$ Diverticulitis-associated abscesses are found at CT in approximately $15 \%$ of patients. ${ }^{[15]}$

Unenhanced helical CT has been shown to be very accurate in the diagnosis of common disorders such as acute appendicitis, renal colic, and diverticulitis in some studies. ${ }^{[16-19]}$ Specific clinical diagnoses, such as pyelonephritis, pancreatitis, aortic dissection, and ischemic bowel, may be best evaluated with the use of intravenous contrast material. ${ }^{[20]}$

According to American College of Radiology ${ }^{[21]}$ contrast material-enhanced CT of the abdomen is considered the most appropriate examination for patients with fever, nonlocalized abdominal pain, and no recent surgery. Rectal and oral contrast material may be helpful in differentiating fluidfilled bowel loops from abscesses in some cases and facilitates detecting intestinal pathologies. ${ }^{[22]}$

Chaan et al. ${ }^{[23]}$ showed that early CT (within 24 hours) enabled appropriate identification of potentially serious surgical conditions, might reduce lenght of hospital stay and mortality. Inaaccurate or delayed diagnosis may lengthen hospital stay and increase health care costs. Many studies have shown that CT findings have a significant contribution to the accuracy of the clinical diagnosis. ${ }^{[2,24]}$

Our aim is to describe the CT findings of the most common conditions of acute abdomen excluding trauma and pediatric or obstetric patients.

\section{Technique or procedure details}

CT accurately images the liver, spleen, retroperitoneum including the adrenals as well as the bowel and mesentery. In the emergency setting, intravenous (IV) contrast is usually administered except renal impairment. Without contrast CT scans are generally preferred for evaluation of renal calculi. Contrast can also be given oral or rectal, but the use of enteral contrast in the emergency setting is limited because of possibility of urgent surgery. We can obtain highresolution sections through the entire abdomen in a single breath-hold with multidedector CT nowadays. Multidetector CT scanners with 16-128 channels allow collection of isotropic voxel datasets with no loss of resolution. ${ }^{[1,7,25]}$
We performed helical scanning with 40-row multidetector $\mathrm{CT}$ at $220 \mathrm{~mA}$ and $120 \mathrm{kVp}$. Transverse images were obtained from the lung bases to the pubic symphysis. The following technique was used: $100 \mathrm{ml}$ of IV iodinated contrast material was injected at $3 \mathrm{ml} / \mathrm{sec}$. Patients ingested $450 \mathrm{ml}$ of a $2 \%$ barium sulfate suspension 1-2 hours before scanning. Thin axial and 5-mm contiguous sections are obtained.

\section{Imaging findings}

\subsection{Acute appendicitis}

Acute appendicitis is the most common causes of acute abdominal pain and overall incidence of appendicitis is approximately $11 / 10,000$ population. ${ }^{[26]}$ Typically acute appendicitis presents with prodromal symptoms of anorexia, nausea and periumbilical pain. The main pathology is luminal obstruction, after 6-8 hours, pain migrates to the right iliac fossa because appendiceal inflammation progresses, the appendix becomes enlarged and eventually touches the parietal peritoneum. Tenderness, rebound occurs after the parietal peritoneum irritation. Classically, the patient has raised serum inflammatory markers. ${ }^{[1,27]}$ The criteria for the diagnosis of appendicitis on CT are enlarged $(>6 \mathrm{~mm})$ fluid filled appendix ${ }^{[28,29]}$ with peri-appendiceal fat stranding. ${ }^{[29,30]}$ Appendicoliths and contrast enhanced thick wall are secondary signs (see Figure 1).

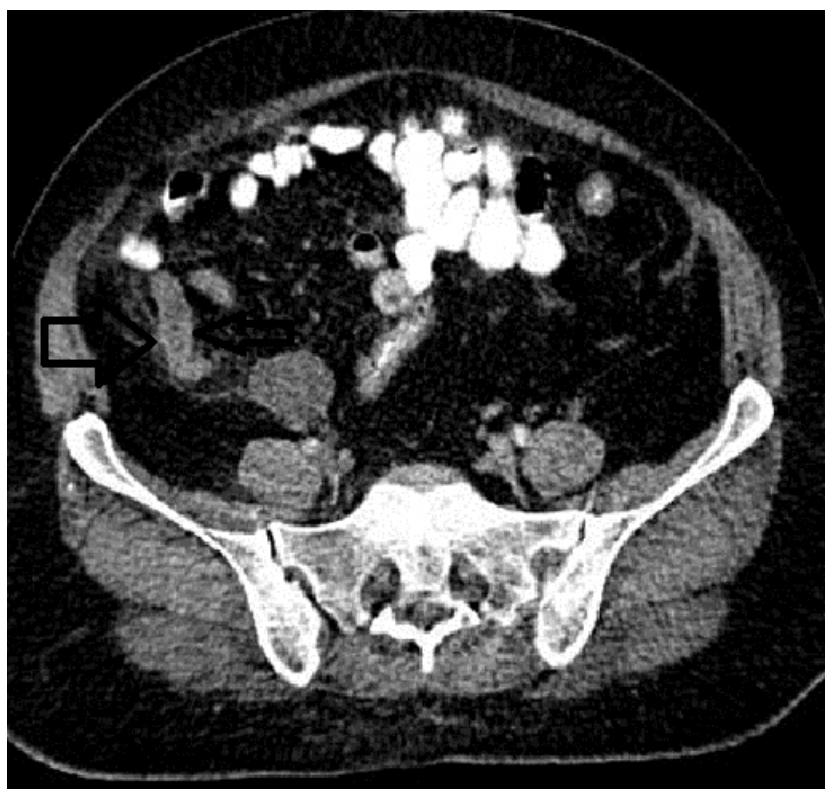

Figure 1: Forty-seven years old, female patient. Axial image CT scan shows enlargement of the appendix with thickened walls (arrow) and adjacent inflammatory stranding. 


\subsection{Epiploic appendagitis}

Epiploic appendagitis is a rare and self limited cause of acute abdomen that manages conservatively. It mostly manifests in the 4th and 5th decades of life with a male predominance. The original pathology is torsion of the appendage resulting in vascular occlusion and inflammatory changes. Although depending on the localization site it can mimic any cause of acute abdominal disease, it is mostly manifested as acute diverticulitis or appendicitis because of same symptom such as localized, severe pain, usually in the right or left lower quadrant. İt is very important to know radiologic characteristics of this condition before unnecessary more aggressively surgery. The typical imaging findings are an oval lesion of fat density with a hyperdense rim and peripheral contrast enhacement. Mesenteric fat planes also are commonly increased in density ${ }^{[30,31]}$ (see Figure 2).

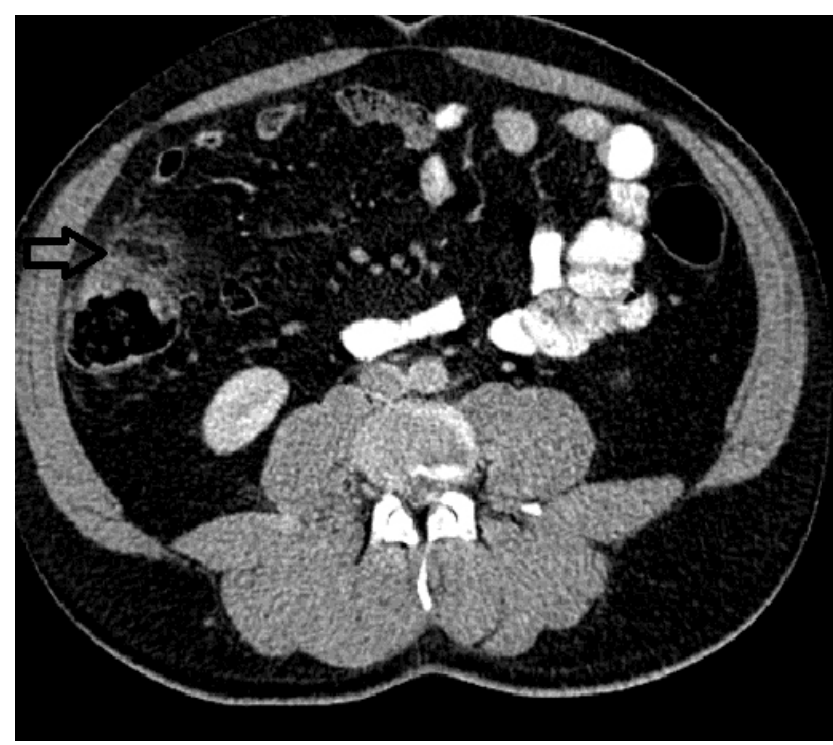

Figure 2: Thirty years old, male patient. CT imaging shows fat density with a hyperdense rim and peripheral contrast enhacement closed to ascending colon (arrow).

\subsection{Acute diverticulitis}

Acute diverticulitis is a common condition and usually effected patients are older than 50 years. Although it can occur anywhere in the large bowel, the most common localization is sigmoid colon and generally patients have fever with abdominal pain in left iliac fossa. On physical examination tenderness and rebound can be determined. CT imaging can show segmental colonic wall thickening and inflammatory changes in the fat surrounding a diverticulum and also complications of diverticulitis such as abscess formation or perforation, can best be excluded with CT. It has a high sensivity of $97 \%$ to confirm true diagnosis of acute diverticulitis $^{[32]}$ (see Figure 3).

Published by Sciedu Press

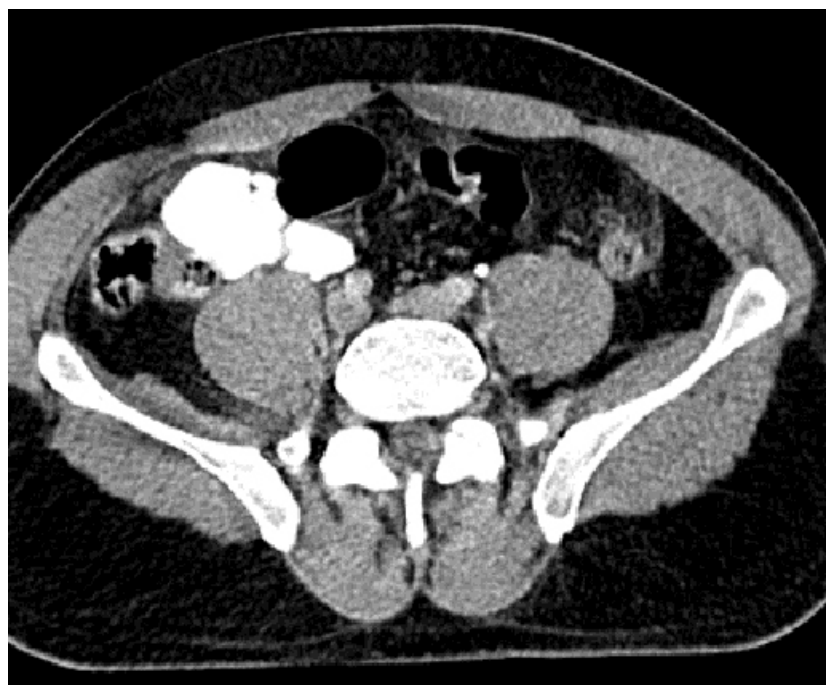

Figure 3: Thirty-five years old, male patient. Axial CT imaging shows high density in the mezenteric fatty tissue and segmental colonic wall thickening closed to descending colon.

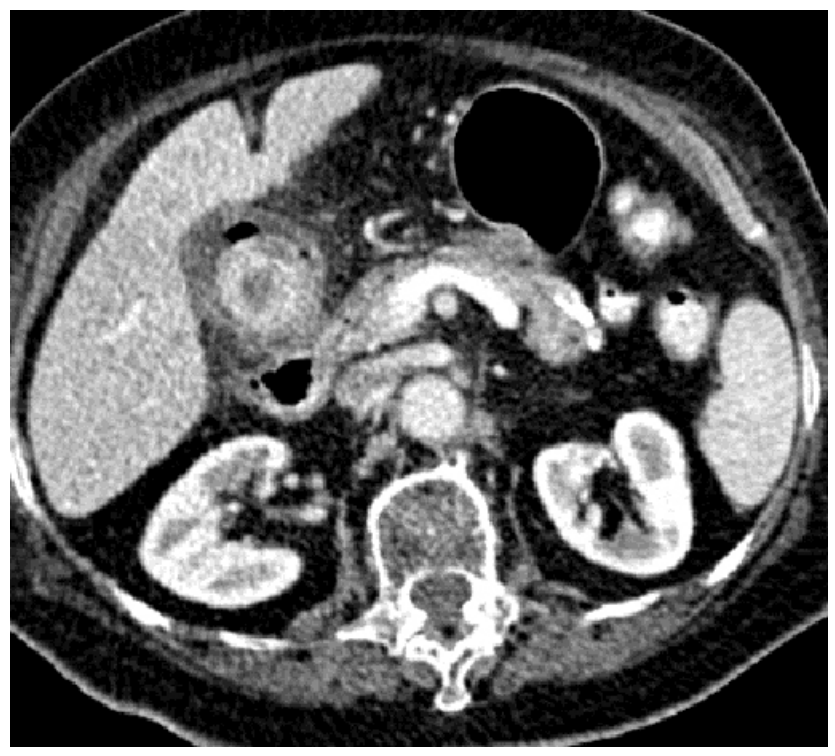

Figure 4: Ninety years old, female patient.

Emphysematous cholecystitis. Axial CT imaging shows hydropic gallbladder, stone in the lumen, air density in the thickened wall and pericholecystic fluid.

\subsection{Acute biliary disease}

Acute biliary disease refers a wide spectrum between biliary pain and acute cholecystitis. Biliary pain usually lasting less than six hours. The most common cause is acute choloecystitis when it presents as a persistent colic pain. Additional symptoms are nausea, vomiting, and low-grade fever with right upper quadrant tenderness and Murphy's sign. The main diagnostic concern is thick-walled gallbladder at imaging. This sign is not pathognomonic alone, additional imag- 
ing signs like obstructing gallstone, distention of gallbladder, pericholecystic fat inflammation or fluid are needed for $\operatorname{diagnosis}^{[33]}$ (see Figure 4).

\subsection{Mesenteric panniculitis}

Mesenteric panniculitis is a rare condition characterised by a chronic, non-specific inflammation affecting the adipose tissue of intestinal loops. Although there is no certain accepted cause yet, a variety of conditions like vasculitis, autoimmunity, infection, trauma, ischaemia, prior abdominal surgery and neoplasm are possible reasons. It occurs most commonly at the age of 50-60 years and presents with abdominal pain, diarrhoea or a palpable mass. Abdominal CT is the most sensitive imaging modality for detecting mesenteric panniculitis but diagnosis is usually confirmed by surgical biopsies. CT feature of the disease is decribed: a "fat ring sign" that involves around the mesenteric vessels composed high density in fatty tissue with or without enlarged mesenteric or retroperitoneal nodes ${ }^{[34-36]}$ (see Figure 5).

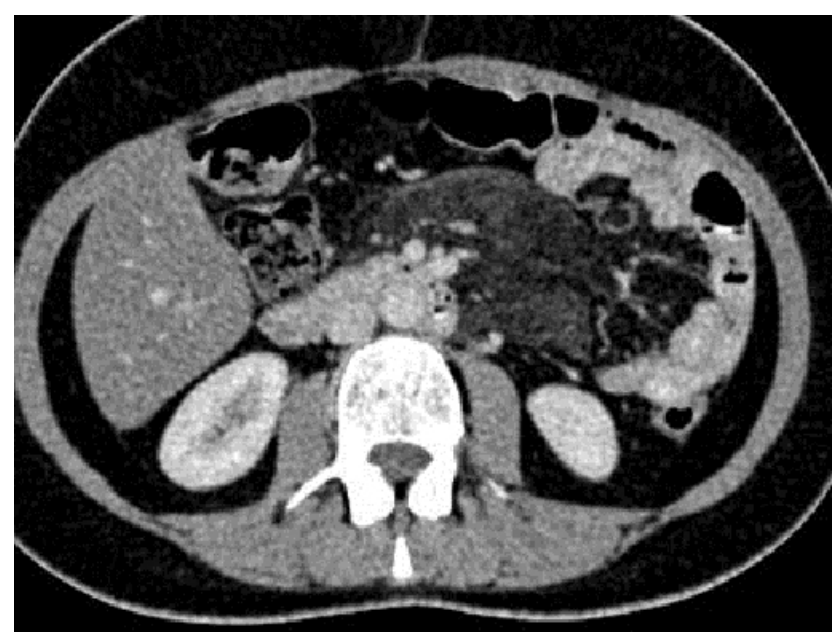

Figure 5: Forty-four years old, female patient. Axial contrast-enhanced CT of mesenteric panniculitis. There is subtle increased density of the fat at the mesenteric root with associated enlarged mesenteric lymph nodes.

\subsection{Perforated peptic ulcer}

Perforation of a peptic ulcer is the most common cause of pneumoperitoneum that is a well-defined mucosal defect of the stomach or duodenum. Patients typically present with the sudden onset of severe, diffuse abdominal pain. On physical examination, rebound, tenderness and abdominal muscular rigidity occur in whole abdomen reveals by peritoneal irritation.

$\mathrm{CT}$ is the most sensitive imaging technique for diagnosis of free intra-peritoneal air by thin slice collimation, and reformatting of images. Free air may travel from the perforation side along the hepatoduodenal ligament into the fissure for ligamentum venosum and be seen adjacent to the portal vein and perihepatic area. There are three CT findings have a high predictivity to detect the site of perforation; concentrated bubbles of extraluminal air close to the perforated area of the bowel wall, focal defect in the bowel wall, and segmental bowel wall thickening ${ }^{[37]}$ (see Figure 6).

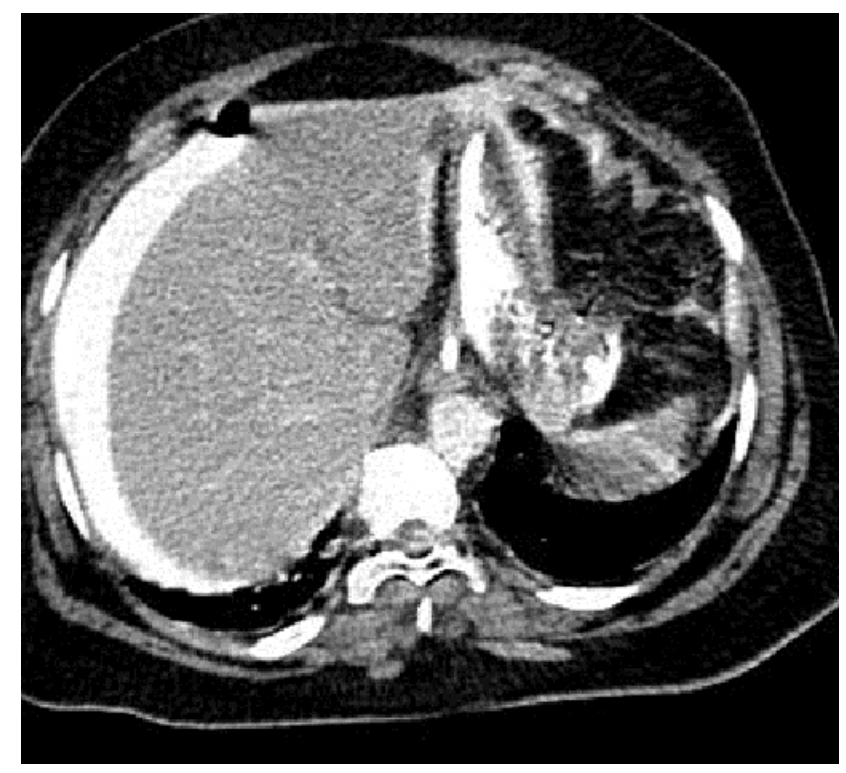

Figure 6: Fifty-six years old, female patient with perforated gastric ulcer. Axial CT image shows pneumoperitoneum, leak of oral contrast material through the focal defect in anterior gastric wall to perihepatic area.

\subsection{Small bowel obstruction}

Small bowel obstruction may occur in any age with different causes. The most common causes in adults are postoperative adhesions and incarcerated hernias while in children intussusception, intestinal atresia, and meconium ileus are the most common causes. Generally symptoms are sudden periumbilical pain, nausea and vomiting. There are dilated loops of small intestine with air-fluid levels and decompressed distal small bowel and colon on plain radiography. $\mathrm{CT}$ is more effective to detect the transitional point (whirl sign) and cause of obstruction ${ }^{[38]}$ (see Figure 7, 8).

\subsection{Bezoar}

Bezoars are composed of foreign materials that are created in the intestinal tract. The most common bezoars are vegetable material (phytobezoars, hair and hair-like material (trichobezoars), persimmon fragments (disopyrobezoars), various medications (pharmacobezoars) and milk curd (lactobezoars). Bezoar-induced small bowel obstruction is a rare condition. It should be suspected in high risk patients such as previous gastric surgery, poor dentition, and a suggestive history of increased fibre intake. The symptoms associated with bezoars are often non-specific. Some patients 
are asymptomatic while others describe epigastric discomfort, bloating, early satiety, nausea, vomiting and weight loss. CT imaging is advocated to be performed early in high risk patients and in patients presenting with small bowel obstruction with or without a history of abdominal surgery in order to reduce unnecessary delays before appropriate surgical intervention $^{[39]}$ (see Figure 9).

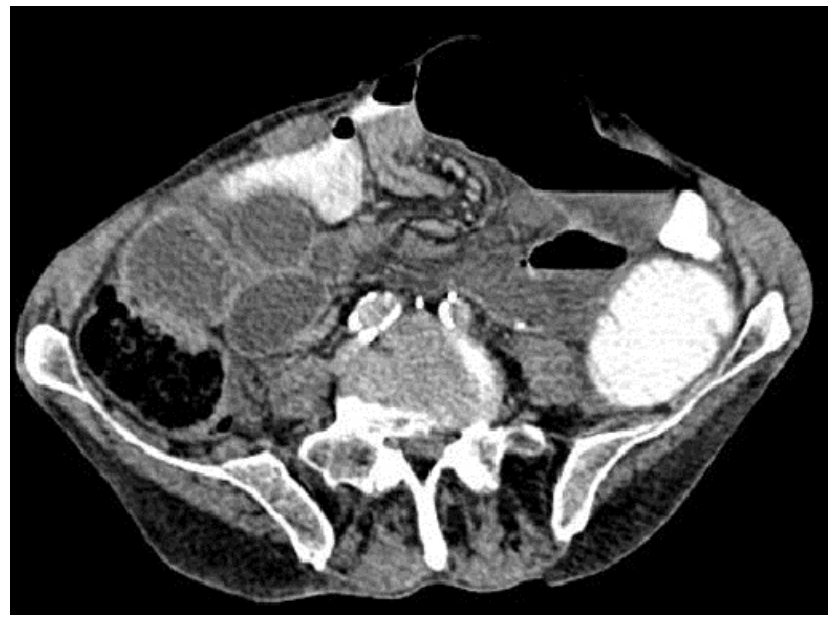

Figure 7: Seventy-six years old, male patient. Axial image CT scan shows whirl "sign" the small bowel is wrapped around SMA.

\subsection{Large bowel obstruction}

The most common causes of large bowel obstruction are carcinomas, inflammatory diseases (diverticulitis, appendicitis), volvulus (cecum, sigmoid), inflammatory intestinal diseases (crohn's disease, ulcerative colitis), metastases, lymphoma and pelvic masses. Another cause of large bowel obstruction is transmesocolic hernia which extremely rare type of internal hernias and accounts for approximately 5\%$10 \%$ of all internal hernias. ${ }^{[40]}$ Also obturator hernia must be considered in the differential diagnosis of thin, elderly patients, especially females, admitted with symptoms of intestinal obstruction. Generally symptoms are the same with small bowel obstruction; patients have abdominal pain, distension, nausea and vomiting. Althought many dilated bowel loops are seen it is difficult to recognize the transitional point on plain radiography. Multidetector CT has a high sensitivity and specificity of $96 \%$ and $94 \%$ in the diagnosis of large bowel obstruction ${ }^{[41]}$ (see Figure 10, Figure 11).

\subsection{Internal hernia}

Internal hernia is a rare condition; it accounts for $0.5 \%$ to $5.8 \%$ of cases of intestinal obstruction. There are different types of internal hernias. Paraduodenal hernia is the most common cause which account $53 \%$ of intestinal obstruction. It has two types: left paraduodenal hernias and right paraduodenal hernias. Another type represents $8 \%$ of patients and the main pathology is omental foraminal herniation. ${ }^{[42]} \mathrm{CT}$ imaging has an important role for diagnosis of intestinal obstruction with these signs, hernia sac containing small intestine in an unusual position with a patient who had no history of abdominal operation (see Figure 12).

\subsection{Ruptured hydatid cyst}

Echinococcus granulosus is an important parasitic disorder which is common in sheep-rearing regions that leads to a significant health problem in undeveloped and developing countries of Mediterranean region. Clinical presentation changes according to the numbers, size, localizations, and complications of the cysts. Rupture into the abdominal cavity is a rare but serious complication of hydatid disease. Rupture can occur spontaneously or following a trauma. Abdominal ultrasonography and computed tomography is effective for diagnosis of ruptured hydatid cyst ${ }^{[43,44]}$ (see Figure 13).
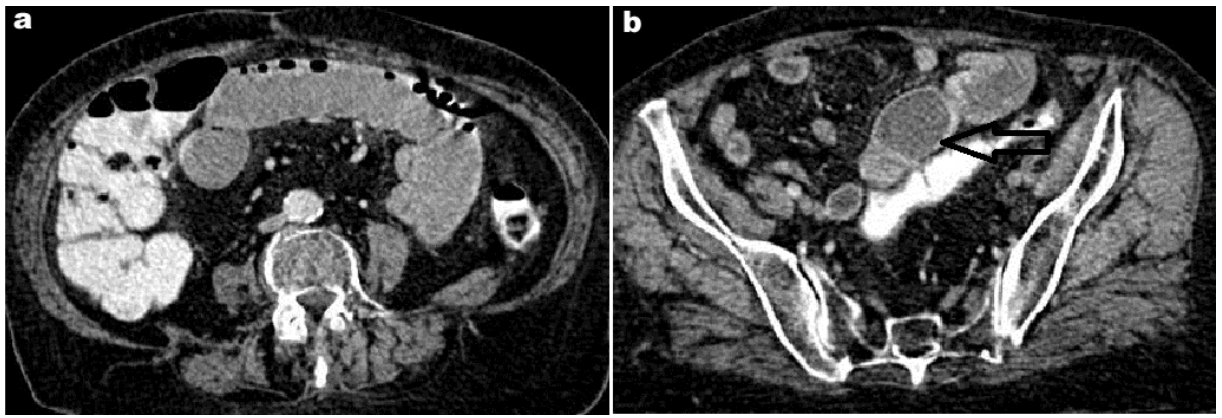

Figure 8: Seventy-eight years old, female patient with gallstone ileus. (a) Axial image CT scan shows air in intrahepatic and common bile ducts with dilatation of small bowel loops. (b) There is a focal, round, low density localizated in the ileum is a gallstone (arrow).

\subsection{Mesenteric ischemia}

Mesenteric ischemia is a rare and potentially life threatening disorder which accounts for $1 \%$ of acute abdomen hospitalizations. If the blood supply to the bowel decreases any further, mesenteric ischemia will develop. Arterial embolus or superior mesenteric artery thrombosis are the most common causes while rare causes are mesenteric venous thrombosis and non-thrombotic mechanical conditions. ${ }^{[42,45,46]} \mathrm{Al}-$ though developed imaging technologies, mortality rates are high because of non-specific and insensitive clinical and laboratory findings. 


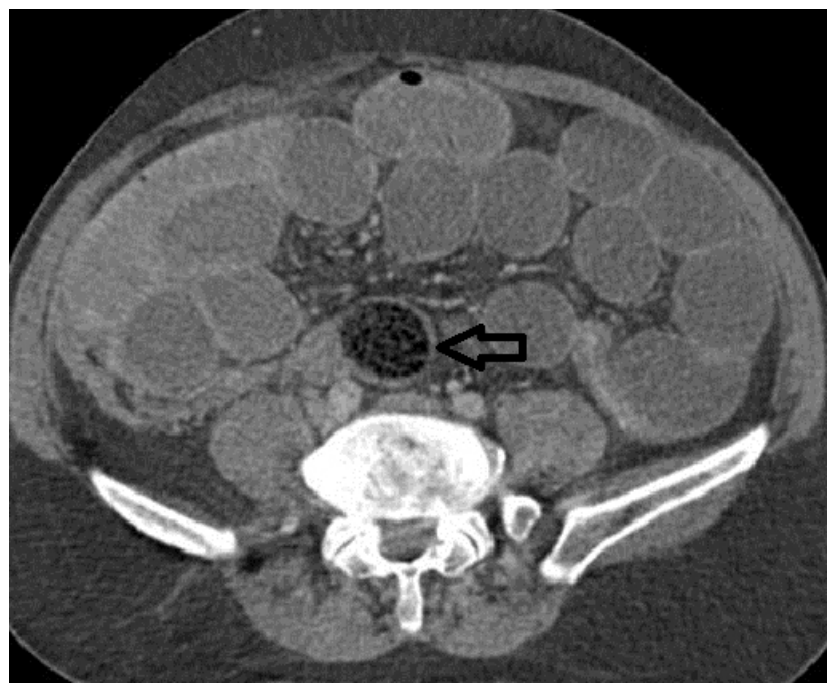

Figure 9: Forty-seven years old, male patient. Small bowel obstruction secondary to the bezoar. Axial CT scans show dilatation of small bowel loops and intraluminal bezoar densities (arrow).
Gold standart imaging technique is catheter angiography, but computed tomography is more available for fast diagnosis in the emergency room. ${ }^{[4]}$ Diagnostic CT findings are submucosal haemorrhage, enhanced-thickened walls of bowel loops and thrombi or emboli in superior mesenteric $\operatorname{artery}^{[1,42]}$ (see Figure 14).

\subsection{Tuberculosis}

Radiological findings of abdominal tuberculosis can mimic those of many different diseases. A high level of suspicion is required, especially in high-risk population. ${ }^{[48]}$ Abdominal tuberculosis, which may involve the gastrointestinal tract, peritoneum, lymph nodes or solid viscera. Abdominal tuberculosis should be considered in patients with fever, abdominal pain, ascites and/or elevated CA-125. This condition has good prognosis if shortly diagnosed and treated. CT scans showed ascites, lymphadenopathy (especially calcified), mesenteric or omental stranding, bowel wall thickening $^{[49]}$ (see Figure 15).

Figure 10: Seventy-four years old, female patient. (a) Axial image CT scan shows free air in the upper quadrant of abdomen (b) Distention of large bowel loops. (c, d) There is a large bowel herniation in right obturator foramen (arrows).

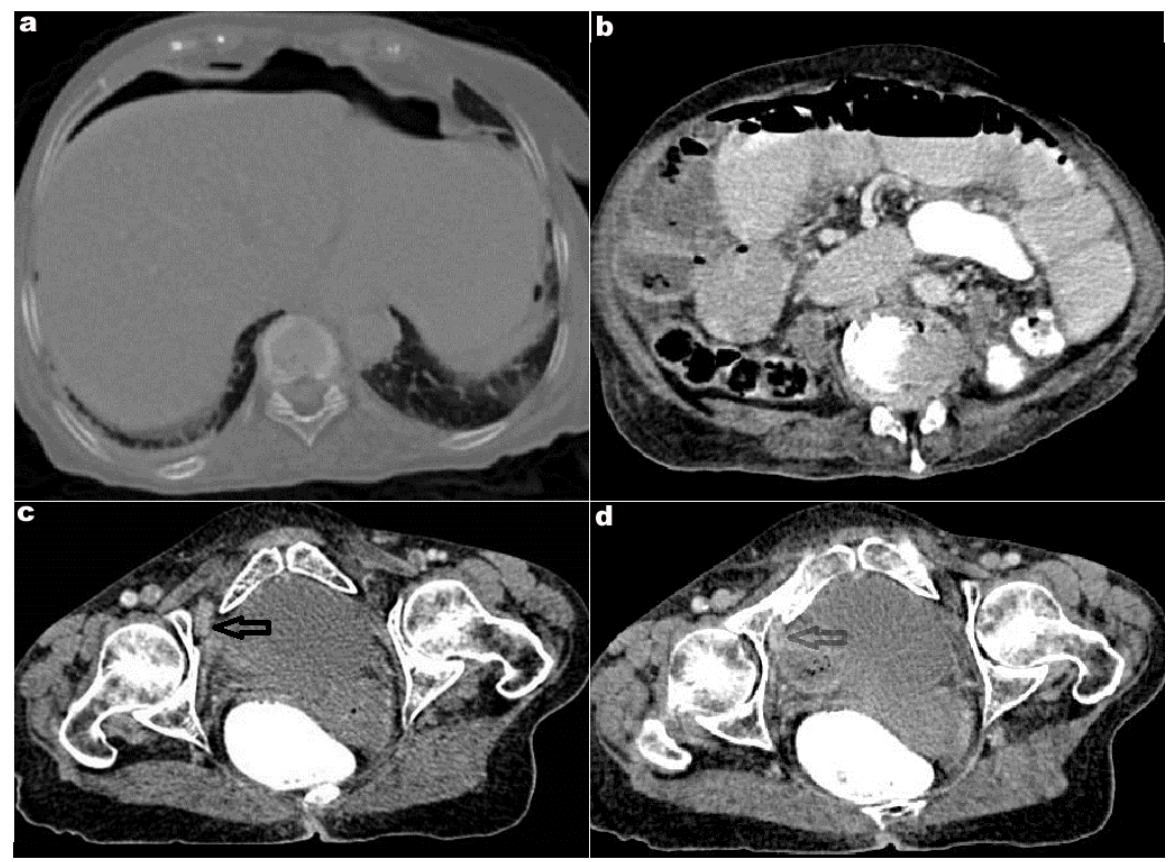

\section{Discussion}

As mentioned earlier four or five percent of patients who admitted to the emergency department have acute abdominal pain. The clinical course is similar on these patients. CT is very useful to differentiate the cause. IV contrast material is mandatory exception of contraindication. Because it is useful for vascular disorders such as aort aneurysm, superior mesenteric artery trombosis, aortic dissection also ischemic bowel disease and acute pancreatitis. ${ }^{[20]}$

But in some conditions we don't use IV contrast material such as renal colic. Because of this, taking the history of the patient is very important. In some circumstances $\mathrm{CT}$ is suitable after abdominal US examination; such as gallstones. CT is very useful on interpreting choledochal calculi especially for the obese patients. Because for the obese patients to interpret choledok and pancreas is difficult with US. Patients with the gallstones and pain in the abdomen have a risk of choledochal calculi and acute pancreatitis. ${ }^{[5,8]}$

Use of oral and rectal contrast agent is also useful to detect small bowel perforation and abcesses. In the small bowel perforation you can detect free air close to perforated small bowel. ${ }^{[22]}$ 


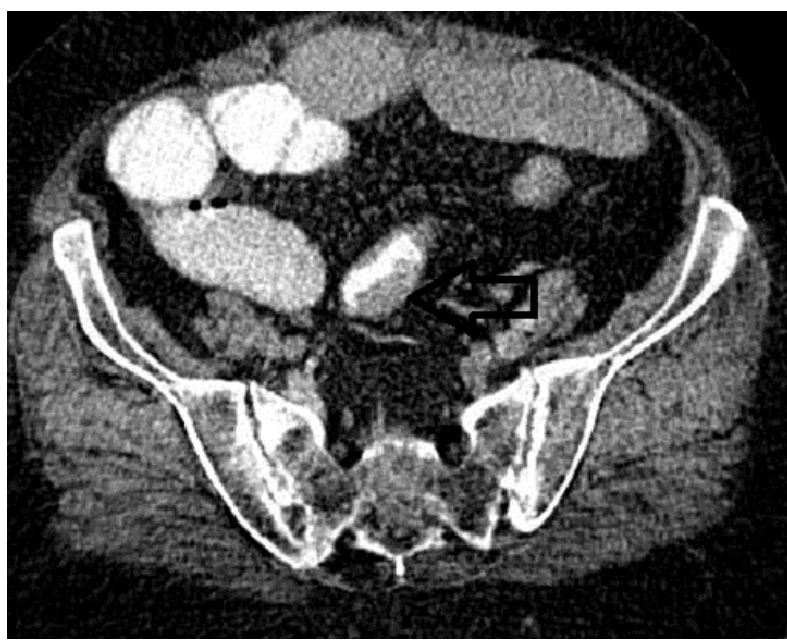

Figure 11: Seventy years old, female patient presented with acute abdominal pain. Axial CT scan shows irregular shape, solid, heterogeneous mass in sigmoid colon (arrow) and dilated small bowel loops.

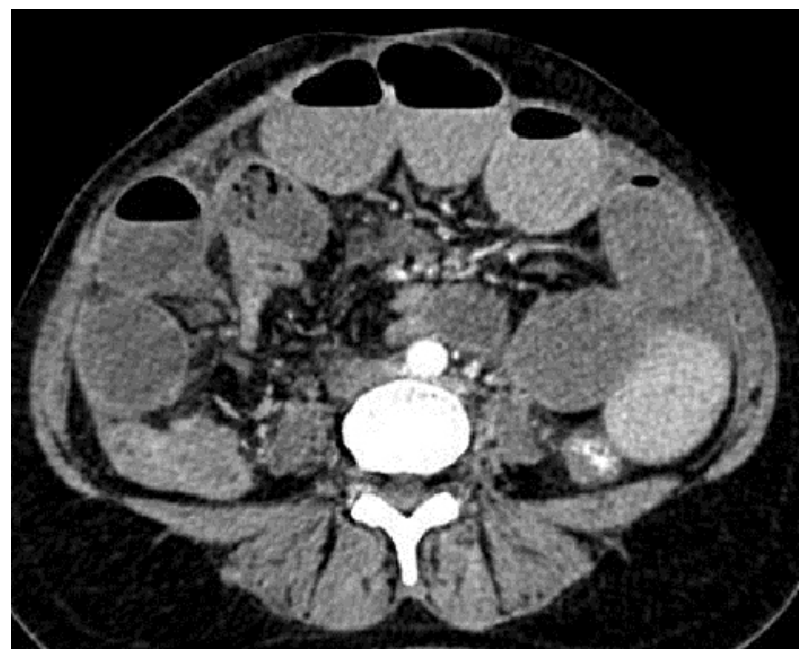

Figure 12: Fifty-two years old, female patient. Fluid-filled loops of small bowel, lateral to ascending colon and lie directly beneath anterior abdominal wall because loops of bowel displacing omental fat.

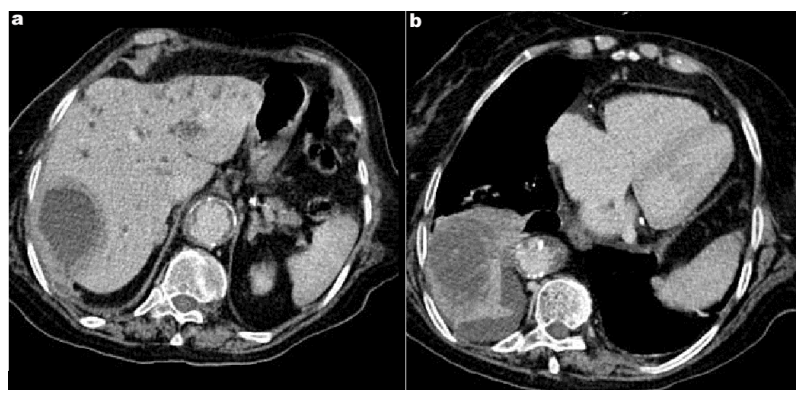

Figure 13: Eighty-two years old, female patient. (a, b) Axial CT images show ruptured liver hydatid cyst to the right pleural space.
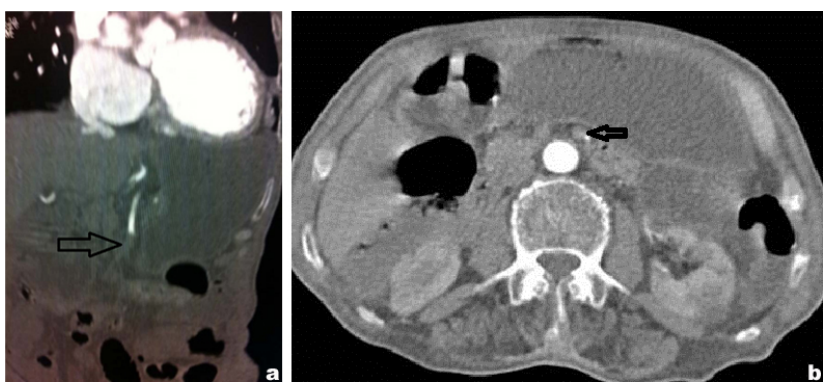

Figure 14: 80 years old, female patient. (a) Coronal CT image show thrombus material within the lumen of the superior mesenteric artery (arrow). (b) Axial CT image show the start of thrombus within the lumen and dilated SMA (arrow).

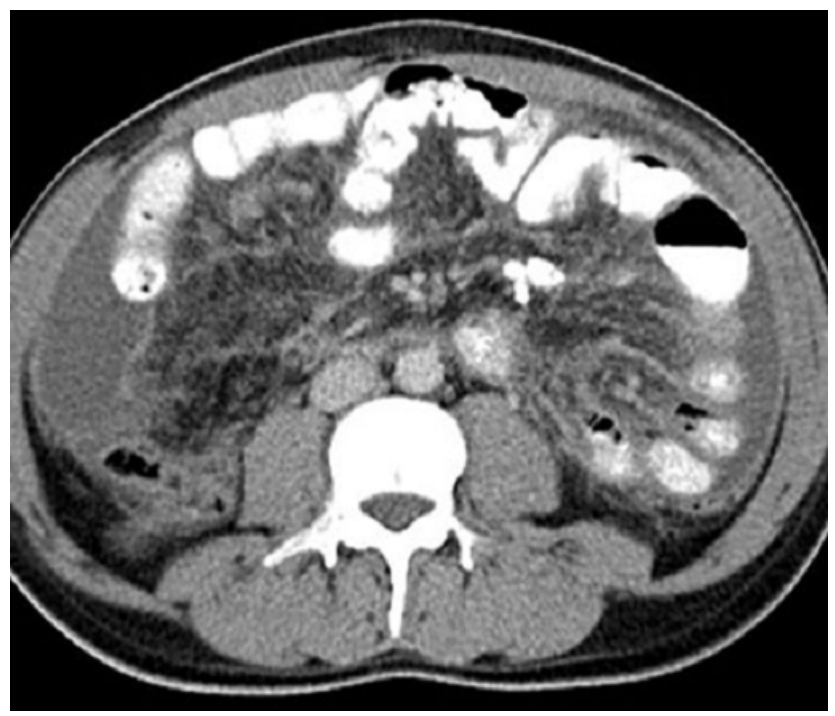

Figure 15: Thirty-two years old, male patient. Axial image CT scan shows increased density of the fat at the mesenteric root with associated calsified mesenteric lymph nodes, ascites and peritoneal contrast enhancement.

There are also some causes of nonsurgical acute abdomen such as epiploic appendagitis. CT is also helpful for avoiding unnecessary surgery. CT is also very useful for evaluating postoperative early complications such as abcessses and late complications such as adhesions. ${ }^{[23]}$

\section{Conclusions}

In patients with acute abdomen, a misdiagnosis may have serious consequences. Imaging plays an increasingly important role in diagnosis of etiology of acute abdomen. CT has become the most important noninvasive imaging procedure to diagnose acute abdomen. During this procedure, first focus on the most common and the most suspicious diseases, second always screen the whole abdomen for pathology. Moreover, CT may help as a guide for planning surgery or management of pathology and help to abdominal drainage procedure. 


\section{References}

[1] Stoker J, van Randen A, Laméris W, Boermeester MA. Imaging Patients with Acute Abdominal Pain. Radiology. 2009 Oct; 253(1): 31-46. PMid: 19789254. http://dx.doi.org/10.1148/radio 1. 2531090302

[2] Rosen MP, Sands DZ, Longmaid HE, Reynolds KF, Wagner M, Raptopoulos V. Impact of Abdominal CT on the Management of Patients Presenting to the Emergency Department with Acute Abdominal Pain. AJR Am J Roentgenol. 2000 May; 174(5): 1391-6. PMid: 10789801. http://dx.doi.org/10.2214/ajr.174.5.1 741391

[3] van Randen A, Laméris W, van Es HW, van Heesewijk HP, van Ramshorst B, Ten Hove W, et al. OPTIMA Study Group. A comparison of the accuracy of ultrasound and computed tomography in common diagnoses causing acute abdominal pain. Eur Radiol. 2011 Jul; 21(7): 1535-45. PMid: 21365197.http://dx.doi.org/10 . 1007/s00330-011-2087-5

[4] Ahn SH, Mayo-Smith WW, Murphy BL, Reinert SE, Cronan JJ. Acute nontraumatic abdominal pain in adult patients: abdominal radiography compared with CT evaluation. Radiology. 2002; 225 : 159-164. PMid: 12355000. http://dx.doi.org/10.1148/rad iol.2251011282

[5] Anyanwu AC, Moalypour SM. Are abdominal radiographs still overutilised in the assessment of acute abdominal pain? a district general hospital audit. J R Coll Surg Edinb. 1998; 43: 267-270. PMid: 9735654.

[6] Gupta K, Bhandari RK, Chander R. Comparative study of plain film abdomen and ultrasound in non-traumatic acute abdomen. Ind $\mathrm{J}$ Radiol Imaging. 2005; 15: 109-115. http://dx.doi.org/10.4103 /0971-3026. 28760

[7] Michael P. Federle. CT of the acute (emergency) abdomen. Eur Radiol Suppl (2005) [Suppl 4]: D100-D104.

[8] Shea JA, Berlin JA, Escarce JJ, et al. Revised estimates of diagnostic test sensitivity and specificity in suspected biliary tract disease. Arch Intern Med. 1994; 154: 2573-2581. PMid: 7979854. http: //dx.doi.org/10.1001/archinte.1994.00420220069008

[9] Walsh PF, Crawford D, Crossling FT, Sutherland GR, Negrette JJ, Shand J. The value of immediate ultrasound in acute abdominal conditions: a critical appraisal. Clin Radiol. 1990; 42: 47-49. http://dx.doi .org/10.1016/S0009-9260(05)81622-8

[10] Dhillon S, Halligan S, Goh V, Matravers P, Chambers A, Remedios D. The therapeutic impact of abdominal ultrasound in patients with acute abdominal symptoms. Clin Radiol. 2002; 57: 268-271. PMid: 12014871. http://dx.doi.org/10.1053/crad. 2001.0862

[11] Shuman WP, Ralls PW, Balfe DM, et al. Imaging evaluation of patients with acute abdominal pain and fever. American College of Radiology. ACR Appropriateness Criteria. Radiology. 2000; 215(Suppl): 209-212. PMid: 11037428.

[12] Puylaert JB. Ultrasonography of the acute abdomen: gastrointestinal conditions. Radiol Clin North Am. 2003; 41: 1227-1242. http: //dx.doi.org/10.1016/S0033-8389(03)00120-9

[13] The 2007 Recommendations of the International Commission on Radiological Protection ICRP publication 103. Ann ICRP. 2007; 37 : 1-332.

[14] Laméris W, Randen A, Bipat S, Bossuyt PM, Boermeester MA, Stoker J. Graded compression ultrasonography and computed tomography in acute colonic diverticulitis: meta-analysis of test accuracy. Eur Radiol. 2008; 18: 2498-2511. PMid: 18523784. http: //dx.doi.org/10.1007/s00330-008-1018-6

[15] Ambrosetti P, Becker C, Terrier F. Colonic diverticulitis: impact of imaging on surgical management-a prospective study of 542 patients. Eur Radiol. 2002; 12: 1145-1149. PMid: 11976860. http: //dx.doi.org/10.1007/s00330-001-1143-y

[16] Lane MJ, Liu DM, Huynh MD, Jeffrey RB, Mindelzun RE, Katz DS. Suspected acute appendicitis: nonenhanced helical CT in 300 con- secutive patients. Radiology. 1999; 213: 341-346. PMid: 10551210.

[17] Lane MJ, Mindelzun RE. Appendicitis and its mimickers. Semin Ultrasound CT MR. 1999; 20: 77-85. http://dx.doi.org/10. 1016/S0887-2171 (99) 90039-2

[18] Smith RC, Levine J, Dalrymple NC, Barish M, Rosenfield AT. Acute flank pain: a modern approach to diagnosis and management. Semin Ultrasound CT MR. 1999; 20: 108-135. http://dx . doi . org/10. 1016/S0887-2171 (99) 90042-2

[19] Malone AJ. Unenhanced CT in the evaluation of the acute abdomen: the community hospital experience. Semin Ultrasound CT MR. 1999; 20: 68-76. http://dx.doi.org/10.1016/S0887-2 171 (99) 90038-0

[20] Urban BA, Fishman EK. Tailored helical CT evaluation of acute abdomen. RadioGraphics. 2000; 20: 725-749. PMid: 10835125. http://dx.doi.org/10.1148/radiographics.20.3.g00m a12725

[21] ACR appropriateness criteria, 2006. American College of Radiology Web site. Available from: http://www.acr.org/SecondaryM ainMenuCategories/quality_safety/app_criteria/pdf/ ExpertPanelonGastrointestinallmaging/AcuteAbdomina 1PainandFeverorSuspectedAbdominalAbscessDoc1. aspx. Accessed October 15, 2008.

[22] Huynh LN, Coughlin BF, Wolfe J, Blank F, Lee SY, Smithline HA. Patient encounter time intervals in the evaluation of emergency department patients requiring abdominopelvic CT: oral contrast versus no contrast. Emerg Radiol. 2004; 10: 310-313. PMid: 15278712.

[23] Ng CS, Watson CJ, Palmer CR, et al. Evaluation of early abdominopelvic computed tomography in patients with acute abdominal pain of unknown cause: prospective randomised study. BMJ. 2002; 325: 1387. http://dx.doi.org/10.1136/bmj.325.737 7.1387

[24] Tsushima Y, Yamada S, Aoki J, Motojima T, Endo K. Effect of contrast-enhanced computed tomography on diagnosis and management of acute abdomen in adults. Clin Radiol. 2002; 57: 507-513. PMid: 12069469. http://dx.doi.org/10.1053/crad.2001.0 925

[25] Paulson EK, Jaffe TA, Thomas J, Harris JP, Nelson RC. MDCT of patients with acute abdominal pain: a new perspective using coronal reformations from submillimeter isotropic voxels. AJR Am J Roentgenol. 2004 Oct; 183(4): 899-906. PMid: 15385279. http: //dx.doi.org/10.2214/ajr.183.4.1830899

[26] Addiss DG, Shaffer N, Fowler B, Tauxe RV. The epidemiology of appendicitis and appendectomy in the United States. Am J Epidemiol. 1990; 132: 910-925. PMid: 2239906.

[27] Kessler N, Cyteval C, Gallix B, et al. Appendicitis: Evaluation of sensitivity, specificity, and predictive values of US, Doppler US, and laboratory findings. Radiology. 2004; 230: 472-478. PMid: 14688403. http://dx.doi.org/10.1148/radiol. 2302 021520

[28] Daly CP, Cohan RH, Francis IR, Caoili EM, Ellis JH, Nan B. Incidence of acute appendicitis in patients with equivocal CT findings. AJR Am J Roentgenol. 2005; 184: 1813-1820. PMid: 15908536. http://dx.doi.org/10.2214/ajr.184.6.01841813

[29] Rao PM. Cecal apical changes with appendicitis: diagnosing appendicitis when the appendix is borderline abnormal or not seen. $\mathbf{J}$ Comput Assist Tomogr. 1999; 23: 55-59. PMid: 10050808. http: //dx.doi.org/10.1097/00004728-199901000-00012

[30] Pereira JM, Sirlin CB, Pinto PS, Jeffrey RB, Stella DL, Casola G. Disproportionate fat stranding: a helpful CT sign in patients with acute abdominal pain. RadioGraphics. 2004; 24: 703-715. PMid: 15143223. http://dx.doi.org/10.1148/rg. 243035084

[31] Singh AK, Gervais DA, Hahn PF, et al. Acute epiploic appendagitis and its mimics. Radiographics. 2005; 25: 1521-1534. PMid: 16284132. http://dx.doi.org/10.1148/rg. 256055030

[32] Ambrosetti P, Grossholz M, Becker C, et al. Computed tomography in acute left colonic diverticulitis. Br J Surg. 1997; 84: 532-4. PMid: 9112910. http://dx.doi.org/10.1002/bjs.1800840427 
[33] Shakespear JS, Shaaban AM, Rezvani M. CT findings of acute cholecystitis and its complications. AJR Am J Roentgenol. 2010 Jun; 194(6): 1523-9. PMid: 20489092. http://dx.doi .org/10. 2214/AJR.09.3640

[34] Bush RW, Hammar SP, Rudolph RH. Sclerosing mesenteritis: response to cyclophosphamide. Arch Intern Med. 1986; 146: 5035. PMid: 3954521. http://dx.doi.org/10.1001/archinte. 1986.00360150113013

[35] Gunduz Y, Tatli AP, Kara RO. Mesenteric panniculitis: a case report and review of the literature. Maedica (Burhar). 2012; 7: 344-7.

[36] Emory TS, Monihan JM, Carr N J, et al. Sclerosing Mesenteritis, Mesenteric Panniculitis and Mesenteric Lipodystrophy: A Single Entity? Am J Surg Pathol. 1997; 21: 392-98. PMid: 9130985. http://dx.doi.org/10.1097/00000478-199704000-00004

[37] Hainaux b, Aneessens E, Bertinotti R, et al. Accuracy of MDCT in Predicting Site of Gastrointestinal Perforation. AJR Am J Roentgenol. 2006; 187: 1179-1183. PMid: 17056902. http://dx .doi.org/10.2214/AJR.05.1179

[38] Frederick H. Millham. Acute abdominal pain. Sleisenger and Fordtran's Gastrointestinal and Liver Disease, 9th edition. Chapter 10. 2010; 158. PMid: 19815690.

[39] Alden H. Harken, Ernest E. Moore. Abernathy's Surgical Secrets, Sixth Edition Chapter. 48: 244-247.

[40] Kuga T, Taniguchi S, Inoue T, Zempo N, Esato K. The occurrence of a strangulated ileus due to a traumatic transmesenteric hernia: report of a case. Surg Today. 2000; 30: 548-550. PMid: 10883470. http://dx.doi.org/10.1007/s005950070126

[41] Teun C van den Heijkant, Bart AC Aerts, Joep A Teijink, Wim A Buurman, Misha DP Luyer. Challenges in diagnosing mesenteric ischemia. World J Gastroenterol. 2013 March 7; 19(9): 1338-1341. PMid: 23538325.
[42] Martin LC, Merkle EM, Thompson WM. Review of internal hernias: radiographic and clinical findings. AJR Am J Roentgenol. 2006; 186: 703-17. PMid: 16498098. http://dx.doi.org/10. 2214/AJR.05.0644

[43] Kurt N, Oncel M, Gulmez S, et al. Spontaneous and traumatic intraperitoneal perforations of hepatic hydatid cysts: a case series. J Gastrointest Surg. 2003; 7: 635-641. http://dx.doi.org/10.1016 /S1091-255X (02) 00434-1

[44] Ozturk G, Aydinli B, Yildirgan M, Basoglu M, Atamanalp SS, Polat $\mathrm{KY}$, et al. Posttraumatic free intraperitoneal rupture of liver cystic echinococcosis: a case series and review of literature. Am J Surg. 2007; 194: 313-316. PMid: 17693274. http://dx.doi .org/10. 1016/j.amjsurg. 2006.11.014

[45] Wiesner W, Hauser A, Steinbrich W. Accuracy of multidetector row computed tomography for the diagnosis of acute bowel ischemia in a non-selected study population. Eur Radiol. 2004; 14: 2347-2356. PMid: 15378337. http://dx.doi.org/10.1007/s00330-004 $-2462-6$

[46] Herbert GS, Steele SR. Acute and chronic mesenteric ischemia. Surg Clin North Am. 2007; 87: 1115-1134. PMid: 17936478. http://dx.doi.org/10.1016/j.suc. 2007.07.016

[47] Schieda N, Fasih N, Shabana W. Triphasic CT in the diagnosis of acute mesenteric ischaemia. Eur Radiol. 2013; 23: 1891-900. PMid: 23471431. http://dx.doi.org/10.1007/s00330-013 $-2797-y$

[48] Pereira JM, Madureira AJ, Vieira A, Ramos I. Abdominal tuberculosis: imaging features. Eur J Radiol. 2005 Aug; 55(2): 173-80. PMid: 15908155.http://dx.doi.org/10.1016/j.ejrad. 200 5.04 .015

[49] Uzunkoy A, Harma M, Harma M. Diagnosis of abdominal tuberculosis: experience from 11 cases and review of the literature. World $\mathrm{J}$ Gastroenterol. 2004 Dec 15; 10(24): 3647-9. PMid: 15534923. 